\title{
Classroom Re-design to Facilitate Student Learning: A Case Study of Changes to a University Classroom
}

\begin{abstract}
Tom Perks ${ }^{1}$, Doug Orr ${ }^{1}$, and Elham Alomari ${ }^{1}$
Abstract: This case study examines the physical aspects of a particular university classroom, and what affect specific changes to the classroom had on the perceptions of students, instructors and observers regarding the room as an effective learning space. We compare survey and focus group data collected from students taking courses in the classroom prior to changes to the physical environment with comparable data from students taking courses in the same classroom after specific changes had been made. Immediately following changes to the classroom, notable increases were observed in reported perceptions of student satisfaction with the physical environment, including perceptions of the classroom as a more effective and engaging learning space. Similar perceptions of improvement as a teaching-learning space were reported by instructors and observers. However, subsequent follow-up data collection and analyses suggested little if any sustained increase in perceptions of efficacy of the room as a learning space; indeed, most reported variables returned to baseline levels. The implications of these findings and their relevance to classroom design nevertheless may provide insight regarding the manner in which physical space might support or even enhance teaching and learning.
\end{abstract}

Keywords: learning spaces, active learning, classrooms, teaching and learning environment, classroom design

For a number of years there has been an on-going pedagogical shift in higher education away from a traditional content delivery model of instruction to more active models of learning in which students play more involved and interactive roles within the classroom (Cornell, 2002; Brown, 2006). This movement has been coupled with the recognition that the traditional university classroom, with its unidirectional design and tiered, fixed theatre-like seating, is insufficient to accommodate what have increasingly become more varied teaching and learning practices. This growing realization that as the nature of teaching and learning evolves so too must teaching and learning spaces has, in recent years, resulted in a heightened interest among scholars in the examination of classroom space and, more specifically, the inquiry into the connection between classroom design and pedagogy and learning (Brooks, 2011).

This study presents findings from an on-going research project examining classroom spaces on a small university campus. The present case study, which is one component of the larger project, compares perceptions of a specific classroom as an effective learning space before and after relatively extensive changes were made to the physical environment of the room. These changes were guided by feedback from students and instructors as well as by existing literature on innovative classroom designs. In particular, we were interested in assessing if these changes

\footnotetext{
${ }^{1}$ University of Lethbridge, Lethbridge, Alberta, Canada
} 
might be perceived to improve the classroom as a learning space, and if so, whether these perceptions were merely transitory or more enduring. ${ }^{2}$

\section{Review of the Literature}

The shift towards a more student-centred pedagogy in higher education has been the result of serious challenges offered by numerous scholars to long-held assumptions about learning processes and the adequacy of lecture-based instruction as an effective pedagogical approach. Of course, these challenges to traditional pedagogical practices in higher education are not new. Indeed, there has been a long history of outspoken and passionate advocates for rethinking how students in higher education have traditionally been expected to learn (Giroux, 1981; Hooks, 1994; Macedo, 1994; McLaren, 1989; Kember, 2009; Bergtrom, 2011). Of the numerous advocates for educational change, Paulo Freire is typically credited as being a leading intellectual voice calling for a more critical pedagogical approach to education. In his seminal volume, The Pedagogy of the Oppressed, Freire (1970/2004) argues that traditional education is based on a teacher-student dichotomy, where the teacher, standing at the front of the room, is considered the sole authority of knowledge, which is then bestowed upon students who are required only to sit and listen passively in rows of desks oriented towards the teacher. Although Freire does not explicitly address in his writings the physical features of the traditional higher education classroom, it is clear that most university and college classrooms are intended to facilitate this traditional model, and are designed and configured with this model in mind.

Of course, those with experience teaching in higher education are often cognizant of the pedagogy implied by the physical structure of most classrooms, and are likely conscious of the impact this structure has on their approaches to teaching and, by extension, student learning (Lizzio, Wilson, \& Simons, 2002). Although the implicit limitations of traditional classroom design and its orientation towards a traditional instructional model are not necessarily insurmountable, the design of most higher education classrooms is, to many educators, far from ideal. And while the question "what are ideal practices for learning?" is clearly a pedagogical one, it is increasingly being seen, too, as a question of classroom design (Hill \& Epps, 2010; Muthyala \& Wei, 2013). As such, there has been a growing number of scholarly works advocating the need for greater awareness of the connection between the design of classrooms and the experiences of teaching and learning, and the necessity to move to designs that are closer to what Freire (1970/2004) has referred to as "humanist" or "libertarian" models - those based on a more democratic relationship between teacher and student - in which students are far more active in their learning and in the construction of content and knowledge (Barr \& Tagg, 1995; Jamieson, 2003; Armbruster, et al, 2009; Ross, 2013). This movement towards more flexible and collaborative classrooms, commonly labelled "active learning classrooms," has been premised, at least implicitly, on the belief that these enhancements will at least support if not improve student learning outcomes. And yet, although there have been a number of works that speak to the importance of classroom design and its connection to learning (Boddington \& Boys, 2011; Boys, 2011; Clark, 2002; Harrison \& Hutton, 2014; Oblinger, 2006), there have been relatively few

\footnotetext{
${ }^{2}$ An interim report (Perks, 2014) provided a cursory examination of some preliminary intermediate data from this study. While this interim report indicated some interesting possible affects arising from the classroom changes, the data referenced was incomplete and thus could be only superficially examined to provide a brief narrative concerning the research. The case study presented here, based on a complete analysis which includes all of the data collected over the course of the study, significantly extends, both empirically and theoretically, this interim report. Journal of the Scholarship of Teaching and Learning, Vol. 16, No. 1, February 2016. 
systematic, empirical studies examining the classroom as a physical space and its connection to teaching and learning (Temple, 2008). In particular, while there is a reasonably large body of research on the redesign of classrooms where the redesign has been coupled with changes to how courses in that classroom are delivered - studies on active learning spaces, such as "SCALE-UP" (Beichner et al., 2007) or "TEAL" (Dori et al., 2003) classrooms, for example - there are few studies that focus specifically on the impact that changes to the physical environment of the classroom, absent of any changes to course content or delivery, have on perceptions of classrooms as learning spaces. The findings from these few studies focusing specifically on the consequences of the physical structure of classrooms in higher education have been mixed.

In an attempt to isolate the impact of the physical environment on student learning, Brooks (2011) reported findings from a pilot project at the University of Minnesota comparing the performance of students taking a first-year biological science course in a traditional classroom with students taking the same course, with identical content and being taught by the same instructor, in a "technologically enhanced classroom" that featured "large, round tables,... switchable laptop technology,... an instructor station from which content is displayed to two large projector screens, ... and wall-mounted glass marker boards around the perimeter of the room" (Brooks, 2011, p. 3). Although the researchers found that, overall, there were no significant differences in the average final grades between classrooms, they did find significant differences in each group's expected final grades based on students' composite ACT (American College Testing) assessment scores, suggesting that those students in the enhanced classroom outperformed their peers in the traditional classroom. Given that they attempted to control for nearly all other factors, the research group concluded that enhanced learning spaces on their own can "improve student learning beyond students' abilities" (Brooks, 2011, p. 7).

Similar studies examining the link between classroom design and learning, however, have been less conclusive. Hill and Epps (2010), for example, using the same design as Brooks (2011) in which two classrooms - one being a "standard" classroom and the other being an "upgraded" classroom - were compared, found that students in the upgraded room were generally more satisfied, but found no difference in the students' perceptions of the overall effectiveness of the teachers in each room, nor any difference in students' expected grades, suggesting that, for at least some measures of the learning environment, classroom design has little or no impact. Another study by Sanders (2013), also using the same design as Brooks (2011) contrasting differently configured classrooms, found that student engagement in lecturebased courses was higher in classroom spaces organized in traditional rows, while student engagement in group-focused courses was higher in classroom spaces organized around grouped tables. Based on this finding Sanders concluded that "[ $t]$ he relationship between student engagement and classroom design must be considered along with class format and learning objectives" (2013, p. 496). In anticipation of our own findings presented here, this conclusion is noteworthy, as it suggests that changes to classroom designs that place greater emphasis on more active student involvement may be of little consequence to student learning, and possibly even be detrimental, if the delivery and content of a course continue to follow a traditional format regardless of the "type" of room the course is taught in.

As these studies suggest, prior work examining the relationship between classroom design and learning has typically involved controlled comparisons of students' experiences in two existing, but distinct classrooms, often with a "traditional" classroom being contrasted with what is seen as an "improved" classroom, all the while attempting to keep all other factors equal. The use of this quasi-experimental method is not entirely surprising, especially given the Journal of the Scholarship of Teaching and Learning, Vol. 16, No. 1, February 2016. 
idiosyncrasies of classroom spaces on most college and university campuses which thus provide ample ready-made and relatively inexpensive and accessible opportunities to contrast different classroom designs. It should be noted that based on this method any findings that show improvements to learning in one room when contrasted with another tend to be used to infer that certain modifications to the latter will improve that classroom as a learning space. At the same time, since no actual physical changes are made to the rooms themselves, these implications are hypotheses only, since the effects of any modifications cannot be directly assessed using this method. In this study we offer an alternative approach to examining the impact of classroom design on learning in which we modify the same classroom, identified in our research as L1050, and collect information on perceptions of this classroom as a learning space before and after the modifications were made. This approach allowed us to collect feedback from both instructors and students on specific features of the room prior to any changes, and hopefully identify modifications which might actually be perceived to have created an improved learning environment. Studies by Brooks (2011) and Hill and Epps (2010) used different, and in some cases contrasting criteria for what was deemed an "improved" classroom, with, for example, one incorporating large round tables in its "improved" design and the other featuring fixed, tiered seating. Our approach, since it involves actual change, allows us to directly test the consequences of some specifically identified physical classroom modifications on perceptions of student engagement and efficacy of the classroom as a learning space, and thus offers a robust test of the consequences of changes to classroom design. With this approach in mind, our primary research question asks: "Can physical improvements to a classroom be perceived to have a positive and lasting impact on the classroom as a learning space?"

\section{Method}

\section{Data Collection and Analysis}

The data upon which our results are based were collected from students, instructors and observers over three consecutive semesters in classes scheduled to be taught in L1050 in the Fall 2012, Winter 2013, and Fall 2013 academic terms. To establish our working samples, prior to the beginning of each semester instructors teaching in L1050 were contacted to inquire if they were interested in participating in the study. Out of 22 instructors who were scheduled to teach in L1050 across the three semesters, 4 instructors in both the Fall 2012 and Winter 2013 semesters, and 5 instructors in the Fall 2013 semester (a 59\% participation rate in total) agreed to participate in this study. These instructors formed a relatively diverse group, representing a variety of courses in different departments and faculties, thus creating a sample which may be considered representative of the population of classes held in L1050. After an instructor agreed to participate, students enrolled in the course were notified about the study and informed that their participation was voluntary. All instructors and students were guaranteed confidentiality and provided informed consent prior to their involvement in this research. Ethical approval was sought and received from the university's Office of Research Ethics (protocol \#2012-057) prior to the collection of any data.

Information regarding the physical environment of L1050, including perceptions of the classroom as a learning space, was gathered using a variety of methods, including in-class surveys, student focus groups, instructor interviews, and in-class observations, with similar methods and instruments used across all three semesters. From our working sample of 482 
students, 372 responded to the in-class survey (153, 128, and 91 in the Fall 2012, Winter 2013 and Fall 2013 semesters, respectively), representing a 77\% response rate, while a total of 14 students participated in the focus groups in the first two semesters of data collection. Unfortunately, despite numerous solicitations, no students volunteered to participate in the scheduled Fall 2013 focus groups. To mitigate this, an online survey was distributed to participating students in Fall 2013 containing a selection of open-ended questions similar in nature to the directing questions used in the previous focus group sessions (the online survey included five questions asking students their thoughts on the configuration or layout of the room, sightlines, furniture, dual screens, and any other comments about the room). Fifteen students completed the online survey in the Fall 2013 semester. It is noteworthy that all of the student data collected in Winter 2013 and Fall 2013 followed substantial modifications to the physical environment of L1050, which were completed during semester break in February 2013. As the in-class survey questions were operationalized using Likert-type scales, we conducted MannWhitney $U$ tests to identify statistically significant changes in student perceptions of the room as a learning space in both Winter 2013 and Fall 2013 semesters relative to baseline, which was established prior to the changes in Fall 2012. It is germane to note that since the changes to the classroom were completed during semester break, students in the Winter 2013 semester experienced the room both before and after the changes were made, and therefore had an explicit point of reference upon which to judge the success, or failure, of the modifications. In contrast, students in Fall 2012 and Fall 2013 may not have had this point of reference, as it is likely that most students were experiencing the room, in either its prior or current form, for the first time. We should also note that preliminary analyses examining differences by age, gender, major, and year of study between samples of students in Fall 2012, Winter 2013, and Fall 2013 were nonsignificant, so we had no reason to suspect that any changes to perceptions across semesters were the result of cohort effects.

\section{Modifications to L1050}

Early in the project L1050 was chosen as a "locus of convenience" in that: 1) it was a space which could be physically reconfigured (to the extent that was required) relatively easily and inexpensively; 2) similar courses, in terms of level and number of students were scheduled in this classroom; and 3) a sufficient number of instructors teaching in the classroom were amenable to participating in the study. Prior to the physical changes, the classroom itself was a non-tiered rectangular 30 ' by $44^{\prime}(9.1 \mathrm{~m}$ by $13.3 \mathrm{~m})$ room that was designated to accommodate 60 students. The room contained moveable tables and chairs, usually configured into rows oriented parallel to the length of the room. Images of the room prior to the changes, with one view from the back of the room and one from the front, are presented in Figure 1. 


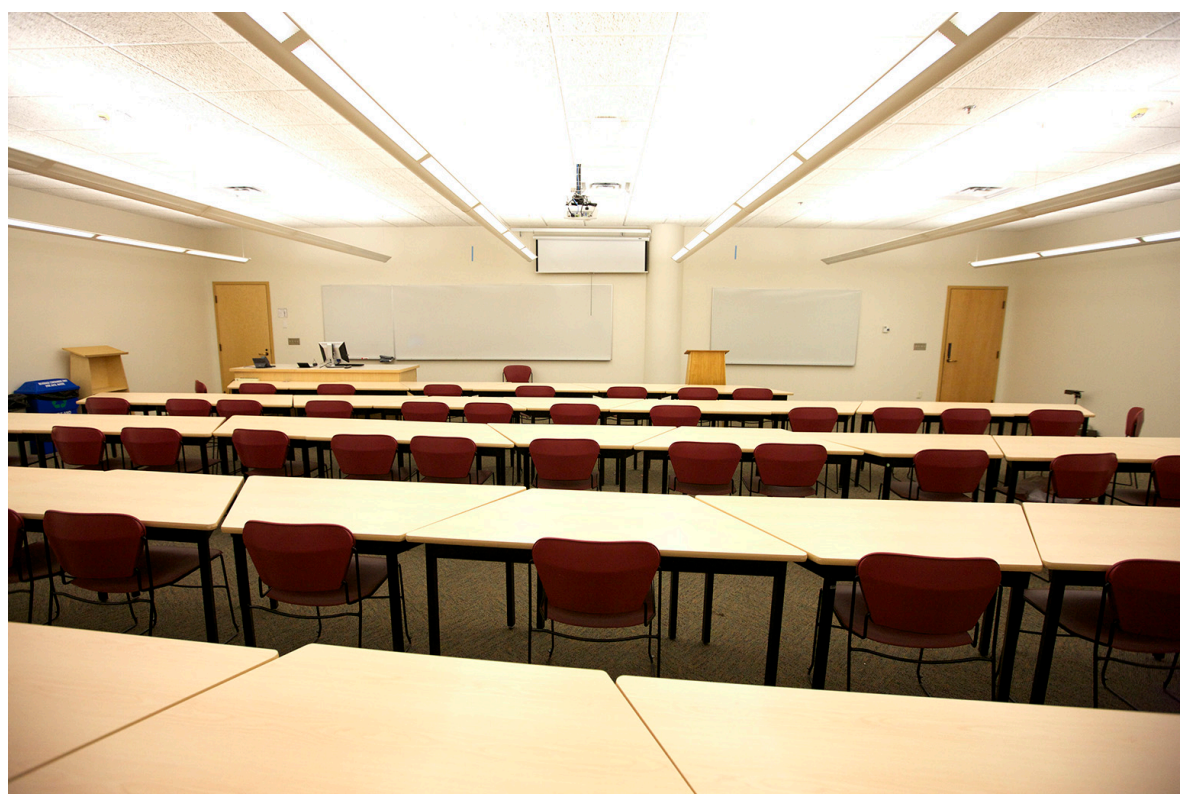

View from the back of the classroom

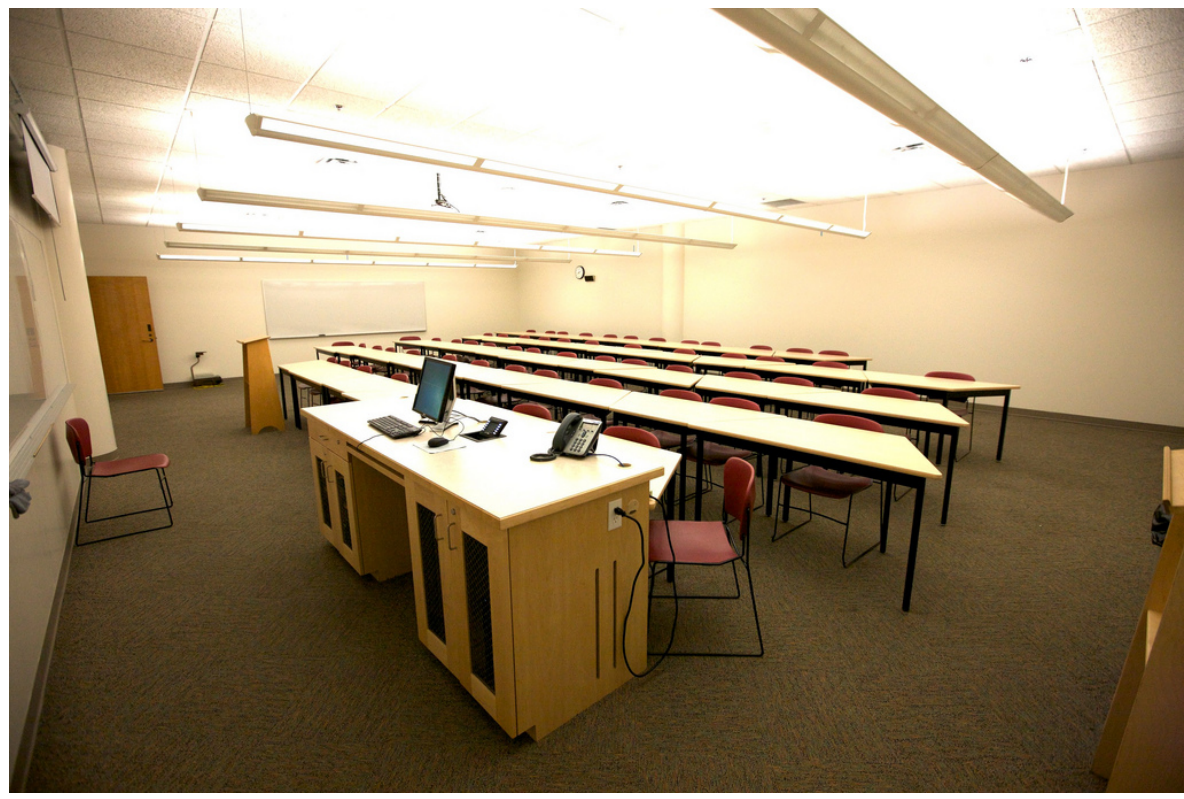

View from the front of the classroom (angled)

Figure 1: Images of L1050 prior to the modifications

The changes made to L1050 were based in part on feedback from students and instructors, collected in Fall 2012, regarding aspects of the room which they reported as being disadvantageous to teaching/learning or adequate but could be improved upon. Although both groups were generally satisfied with the room, criticisms tended to focus on the size and location of the whiteboard, inadequate sightlines, the relative inflexibility of the room configuration, the number of student desks in the room, the size and location of the instructor workstation, and the size and location of the digitally projected image. In addition to this feedback, our decisions regarding possible changes to L1050 were also informed by a comprehensive literature review Journal of the Scholarship of Teaching and Learning, Vol. 16, No. 1, February 2016. 
on innovative design recommendations for learning spaces conducted by the project research group in Summer 2012. This review pointed to many important features of "improved" classrooms, perhaps the foremost being flexibility, sensory stimulation, technology support, and decenteredness (Van Note Chism, 2006). Freire's (1970/2004) notion of a more humanist model of education, too, guided our modifications, with features promoting student-to-student collaboration being particularly prominent in our decision making. With this information in mind, the following changes to L1050 (see Figure 2) were made:

- Reversing the room orientation front-to-back

- Reducing the seating in the room to accommodate a maximum of 40 students

- Re-configuring the student seating into four rows of six trapezoidal tables accommodating ten seats per row; with a centre aisle in each row (three tables of five seats on either side)

- Extending the continuous usable length of the whiteboard at the (new) front of class to 20'

- Moving the whiteboard forward to just in front of the pillar on the (new) front wall

- Replacing the existing digital projector and screen with two 80" LED High-Definition display monitors located on either side of the whiteboard

- Reducing the size of the instructor workstation and placing it to one side of the centre aisle

- Adding a SMART Podium ${ }^{\mathrm{TM}}$ and document camera to the classroom technology suite

- Painting each side wall blue

\section{Results}

Initial Findings in Winter 2013

The findings from the in-class student surveys administered within the first few weeks following the changes to L1050 were for the most part consistently positive about the room changes. These findings, comparing the mean ranks on student responses to the survey questions prior to the changes to the room in Fall 2012 with responses in Winter 2013 following the changes are reported in Table 1. As indicated, based on Mann-Whitney U tests, there were statistically significant improvements across semesters on measures of reported student perceptions of the room as an effective learning space. For example, in response to the question asking students about their general feelings about the room as a learning space, the findings show a significant increase ( $\mathrm{p} \leq 0.001)$ in mean ranks (i.e., a shift in responses away from "hate it" and towards "love it") between the pre- and post-room results in the Fall 2012 and Winter 2013 semesters. Statistically significant $(\mathrm{p} \leq 0.001)$ increases to mean ranks are also observed for questions asking students about whether the classroom is an effective space to hold this course, whether it facilitates different teaching and learning activities, whether the room is a physically comfortable learning environment, and whether the room facilitates student engagement in the learning process. Significant improvements to reported student perceptions regarding specific physical features of the classroom, including room configuration, sightlines, and the colour of the walls, were also found, along with more modest, but still significant improvements to perceptions regarding temperature, sound quality, furniture, and improvements to noise levels emanating from outside the room. The only non-significant difference across semesters was reported perceptions of the lighting in the room. 


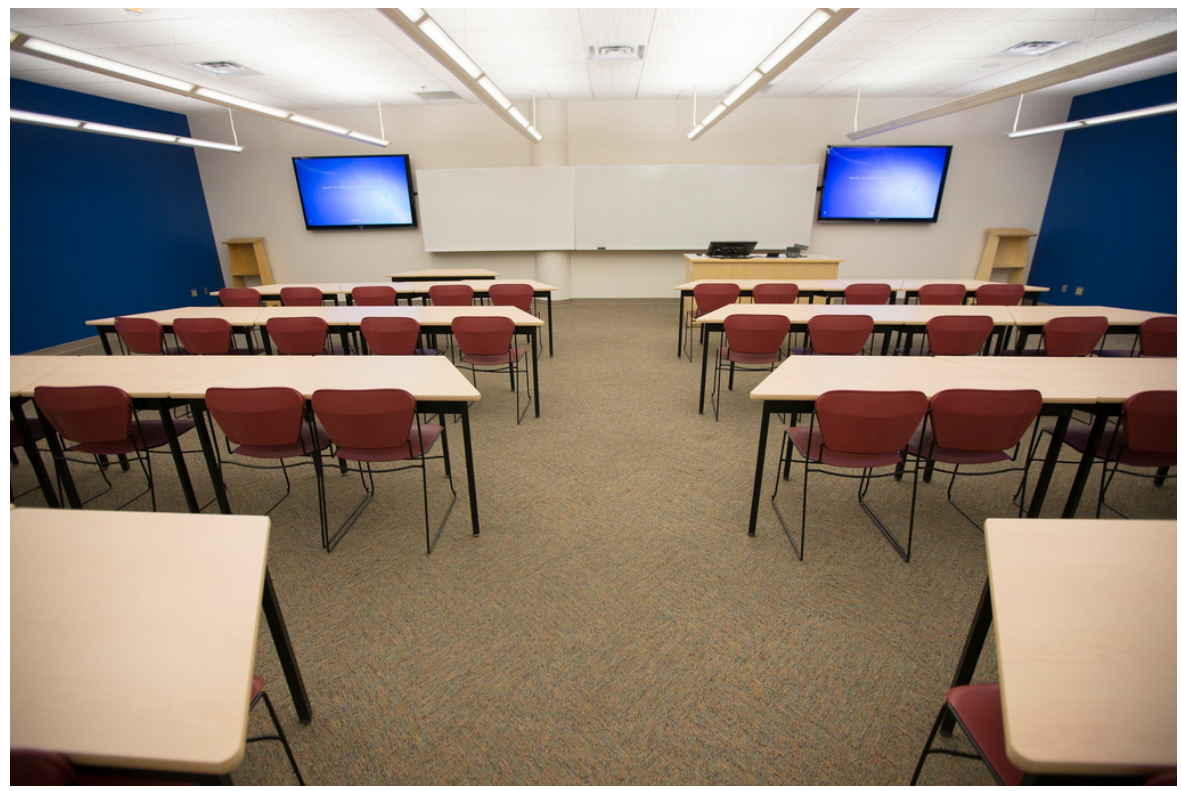

View from the back of the classroom

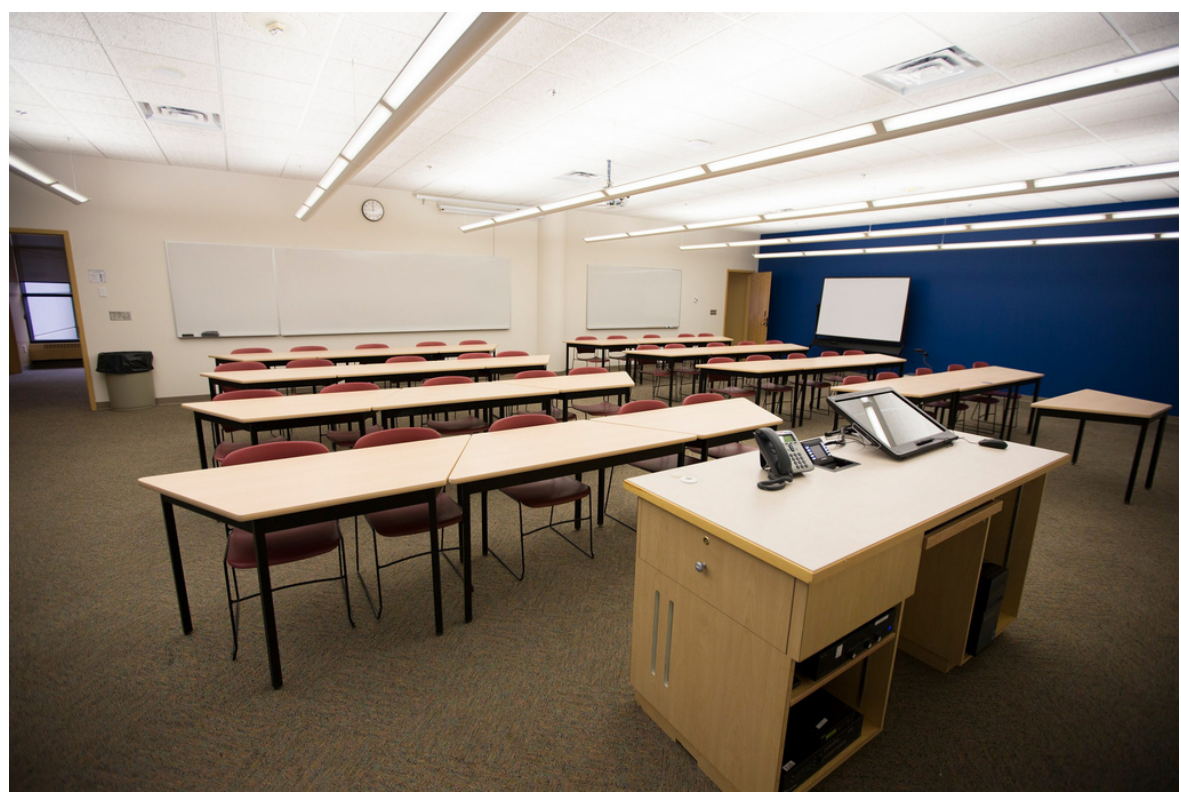

View from the front of the classroom (angled)

\section{Figure 2: Images of L1050 after the modifications}

The feedback elicited during the student focus group interviews, collected in Winter 2013, support many of the patterns of improvement found in the student survey data, in that it too indicates an almost consistently positive response to the room changes. In particular, students responded very favourably to the reduced number of tables/chairs and the reconfiguration of the furniture on either side of a centre aisle, commenting on an improved sense of engagement with class activities and enhanced instructor-student and student-student communication. Students reported that "Now you can see each other more easily," "Before [the renovation] people sat more spread out, all over the place," "The new setup [makes] me more connected," and "With

Journal of the Scholarship of Teaching and Learning, Vol. 16, No. 1, February 2016.

Josotl.Indiana.edu 
more space [the instructor] is able to wander more." Additionally, in classes where collaborative or cooperative work was an important component of the instructional design, the ease of forming smaller work groups and then re-forming for whole-class instruction was noted. Students suggested "[The] furniture is awesome for group work" and "Before [the] renovation we were unable to work in groups due to the rows. It was hard to reconfigure them in to pods ... Now [after the renovation] we can easily formulate (sic) pods." Furniture reduction and reconfiguration was also noted to have improved student sightlines to both the instructor and presentation materials, with one students indicating "I think it is easier to see the instructor."

\section{Table 1. Mean ranks on responses to survey questions in Fall 2012 and Winter 2013}

\begin{tabular}{|c|c|c|}
\hline & $\begin{array}{l}\text { Fall } 2012 \\
(N=151)^{\mathrm{a}}\end{array}$ & $\begin{array}{l}\text { Winter } 2013 \\
(N=127)^{\mathrm{a}}\end{array}$ \\
\hline $\begin{array}{l}\text { Generally, how do you feel about this classroom as a learning } \\
\text { space? }\end{array}$ & 112.6 & $174.0 * * *$ \\
\hline \multicolumn{3}{|l|}{ The classroom in which I am taking this course ${ }^{c}$} \\
\hline ...is an effective space to hold this particular course & 122.8 & $161.6 * * *$ \\
\hline ...facilitates different types of teaching/learning activities & 123.2 & $161.4 * * *$ \\
\hline ...offers a physically comfortable learning environment & 118.4 & $167.1 * * *$ \\
\hline ...facilitates student engagement in the learning process & 123.1 & $162.4 * * *$ \\
\hline \multicolumn{3}{|l|}{$\begin{array}{l}\text { How do you feel about the following aspects of this classroom as } \\
\text { a learning space }\end{array}$} \\
\hline ...room configuration & 111.1 & $172.0 * * *$ \\
\hline ...sightlines & 122.9 & $161.7 * * *$ \\
\hline ...colour of the walls & 101.8 & $184.4 * * *$ \\
\hline ...lighting & 134.5 & $147.8^{\mathrm{ns}}$ \\
\hline ...temperature & 130.8 & $152.2 * *$ \\
\hline ...furniture & 124.4 & $157.5 * * *$ \\
\hline ...sound quality & 127.0 & $156.7 * * *$ \\
\hline ...noise level & 131.7 & $151.2 *$ \\
\hline
\end{tabular}

${ }^{a}$ Represents the smallest number of valid cases across questions

${ }^{\mathrm{b}} 1=$ hate it, $2=$ dislike it, $3=$ neutral, $4=$ like it, $5=$ love it

${ }^{\mathrm{c}} 1=$ strongly disagree, $2=$ disagree, $3=$ agree, $4=$ strongly agree

${ }^{\mathrm{d}} 1=$ very dissatisfied, $2=$ dissatisfied, $3=$ satisfied, $4=$ very satisfied

${ }^{\mathrm{ns}}$ non-significant; $* \mathrm{p} \leq .05 ; * * \mathrm{p} \leq .01 ; * * * \mathrm{p} \leq .001$ (determined using Mann-Whitney U tests)

Having a continuous length of easily visible whiteboard was also positively highlighted (the previous configuration of the room had two white boards, separated by a pillar). A student commented that "The front whiteboard looks better after renovations because it is continuous and larger now, giving more space to write." Interestingly, the colour of the walls was cited as having a favourable influence on the aesthetic of the room as well as positively impacting the effectiveness of the room lighting (although this was not evident in the survey data), eliciting comments that the room now seemed "warmer", "more intimate", "more stimulating", "more comfortable", and "less institutional", while the lighting appeared to be "less harsh". Reversing the room orientation was noted by students as reducing the disruption and distraction caused by students entering and exiting the class, and easing traffic flow into and out of the room. Replacement of the traditional projector and screen, however, received mixed reactions. While Journal of the Scholarship of Teaching and Learning, Vol. 16, No. 1, February 2016.

Josotl.Indiana.edu 
some students commented on improved image clarity and view-ability, others reported two screens to be more distracting. Though one student indicated "I like the new TV screens, they give a direct, clear, and sharper image than the projector screen," others reported "[I'm] not a fan of the TVs, I don't know where to look" and "I don't like the two [screens] on each side." Students particularly commented on the difficulty arising from viewing a monitor from one side of the room while the instructor was speaking from the centre (or pointing to something on the other monitor), indicating, for example, that "look[ing] and listen[ing] to the teacher, you're trying to look where she's pointing, but she's pointing at the other [TV]."

\section{Follow-up Findings in Fall 2013}

In Table 2, findings from the Fall 2013 follow-up survey are presented, to examine if the improved reported perceptions of L1050 as a learning space persisted beyond the semester in which the modifications were made, as well as if they existed among students who were likely experiencing the room for the first time. Based on the mean ranks detailed in the table, with the exception of facilitating different types of teaching/learning activities (significant at $\mathrm{p} \leq .05$ ) and colour of the walls (significant at $\mathrm{p} \leq .001$ ), it appears that reported student perceptions of L1050 as a learning space in Fall 2013 returned to baseline, in that there were no statistically significant differences between Fall 2012 and Fall 2013 semesters on the majority of measures.

Table 2. Mean ranks on responses to survey questions in Fall 2012 and Fall 2013

\begin{tabular}{|c|c|c|}
\hline & $\begin{array}{l}\text { Fall 2012 } \\
(N=151)^{\mathrm{a}}\end{array}$ & $\begin{array}{l}\text { Fall } 2013 \\
(N=90)^{\mathrm{a}}\end{array}$ \\
\hline $\begin{array}{l}\text { Generally, how do you feel about this classroom as a learning } \\
\text { space? }\end{array}$ & 118.9 & $128.5^{\mathrm{ns}}$ \\
\hline \multicolumn{3}{|l|}{ The classroom in which I am taking this course ${ }^{c}$} \\
\hline ...is an effective space to hold this particular course & 119.6 & $126.0^{\mathrm{ns}}$ \\
\hline ...facilitates different types of teaching/learning activities & 115.1 & $135.0 *$ \\
\hline ...offers a physically comfortable learning environment & 117.2 & $131.5^{\mathrm{ns}}$ \\
\hline ...facilitates student engagement in the learning process & 118.9 & $128.5^{\mathrm{ns}}$ \\
\hline \multicolumn{3}{|l|}{$\begin{array}{l}\text { How do you feel about the following aspects of this classroom as } \\
\text { a learning space }\end{array}$} \\
\hline ...room configuration & 115.6 & $128.7^{\mathrm{ns}}$ \\
\hline ...sightlines & 124.4 & $117.9^{\mathrm{ns}}$ \\
\hline ...colour of the walls & 107.2 & $144.2 * * *$ \\
\hline ...lighting & 121.5 & $122.9^{\mathrm{ns}}$ \\
\hline ...temperature & 122.8 & $122.0^{\mathrm{ns}}$ \\
\hline ...furniture & 118.0 & $126.0^{\mathrm{ns}}$ \\
\hline ...sound quality & 118.8 & $128.7^{\mathrm{ns}}$ \\
\hline ...noise level & 119.0 & $128.4^{\mathrm{ns}}$ \\
\hline
\end{tabular}

${ }^{\mathrm{a}}$ Represents the smallest number of valid cases across questions

${ }^{\mathrm{b}} 1=$ hate it, $2=$ dislike it, $3=$ neutral, $4=$ like it, $5=$ love it

${ }^{\mathrm{c}} 1=$ strongly disagree, $2=$ disagree, $3=$ agree, $4=$ strongly agree

${ }^{\mathrm{d}} 1=$ very dissatisfied, $2=$ dissatisfied, $3=$ satisfied, $4=$ very satisfied

${ }^{\mathrm{ns}}$ non-significant; ${ }^{*} \mathrm{p} \leq .05 ; * * \mathrm{p} \leq .01 ; * * \mathrm{p} \leq .001$ (determined using Mann-Whitney U tests) 
The qualitative data based on the open-ended online surveys administered in Fall 2013 were also less supportive of the room in its modified form compared to the qualitative (focus group) data from Winter 2013. In particular, student comments were suggestive of more average or non-committal positions. For example, the question in the online survey inquiring about students' thoughts on room configuration elicited a large number of neutral comments, including comments such as the room configuration was "fine," "I am neither satisfied nor dissatisfied," or "the room configuration is adequate." In addition to inquiring about room configuration, we also asked students their thoughts on sightlines and furniture in the classroom. Again, the comments were generally non-committal, suggesting that students were generally satisfied with these features of the room, but did not necessarily see them as an improvement over most other classrooms on campus. Typical of these comments is: "The furniture is pretty standard throughout the university so it's difficult for me to draw a comparison." Feedback from the question asking students about the dual screens, in contrast to the more mixed feedback from the Winter 2013 focus groups, was generally more negative, with a number of students touching on the idea that the dual screens, in combination with the instructor work station being on one side of the centre aisle, "divided the focus and the class" and led to the perception that instructors tended "to teach to only one side of the class at a time rather than engaging the entire class." Nevertheless, although relatively small in number, there were some students who commented positively about the dual screens, emphasizing, in particular, the ability to see the projected content from anywhere in the room.

\section{Discussion}

The purpose of this study was to examine whether physical modifications to a university classroom, identified here as L1050, could potentially be perceived to improve that room as a learning space. In particular, we wanted to see if design improvements emphasizing flexibility and collaboration, among other changes, could enhance the perceived learning experiences of students in that classroom, and whether such possible perceived improvements would persist over time. What do our findings suggest about the success of these classroom modifications? Immediately following the changes in Winter 2013, results from both the in-class surveys and focus groups suggest that students were, with the exception of their reported perceptions of the dual screens, for the most part supportive of the changes made to the room, and generally perceived the room to be a more effective learning environment relative to its previous design. Certainly, these initial data support the changes made to particular features of the classroom, including the room and furniture reconfiguration, the reduction in the number of student spaces in the room, improvements to the whiteboard space, and painting the side walls. Conversely, the follow-up findings in Fall 2013, from both the in-class and online open ended surveys, were less indicative of perceived improvement, and in most cases statistically returned to baseline. How, then, should these discrepant findings be interpreted?

One interpretation, it seems, is that students in the Winter 2013 semester were merely reacting to the fact that the room was changed rather than to the changes themselves. Put differently, despite our satisfaction with the apparent success of the improvements to the classroom environment immediately following the changes, we were also conscious of the fact that some significant improvements were evident among features that we did not explicitly modify, such as temperature and sound quality. Although it is conceivable that adding colour to the walls made the room feel warmer, and that reducing the number of seats decreased the Journal of the Scholarship of Teaching and Learning, Vol. 16, No. 1, February 2016. Josotl.Indiana.edu 
distance between students as well as between students and the instructor and thus improved the overall sound quality, it is equally plausible that the general improvements to students' perceptions of the room after the modifications were the result of some kind of "Hawthorne" or "novelty" effect (Neuman, 1977), where the students in Winter 2013 were aware of our intention to improve L1050 as a learning space and responded accordingly. Our study, thus, should perhaps be viewed as a cautionary tale for others examining the consequences of classroom modifications on student learning, where researchers examining modifications to the classroom need to be circumspect regarding claims of success without subsequent follow-up data supporting initially positive results. At the same time, students in Fall 2013 were also aware of the goals and intentions of the study since informed consent was provided prior to their involvement. As such, if a reactivity effect was operating, we might expect to see improved perceptions among these students as well, and, as the findings show, there were few improvements. This, to some extent at least, speaks against a reactivity effect and may instead point to other, more noteworthy interpretations.

A further interpretation of the conflicting findings that we suggest may be reasonable, given the nature of the feedback that we received from instructors, is that the success of the room changes may be materially dependent on how the redesigned room was utilized for instruction. As we have noted, L1050 was expressly redesigned with a more active learning pedagogy in mind. However, we did not have any control over what courses were taught in L1050, nor did we have any influence over how the course content across these various courses was delivered. We might speculate that courses incorporating a more active learning model would lead to more positive perceptions of the room as the learning space, whereas courses following a more traditional lecture-based model would likely show limited improvement. After all, L1050 was, prior to the modifications, a relatively modern classroom, with most of its features, such as seating, technology, and lighting, at least adequate for lecture-based pedagogies. After the modifications L1050, based on the reported perceptions of instructors, was neither more nor less detrimental to traditional lecture format delivery. As an active learning space, however, particularly with respect to the reduced number of seats and less congestion in the room, the redesigned version of L1050 was reported by instructors to be more conducive to supporting active learning pedagogies. We know from the instructor interviews we conducted that three out of the four instructors who participated in the study in Winter 2013 made use of a more active learning approach, typically involving students at different points throughout the semester rearranging their desks into "pods" and working in groups on in-class problems or assignments. Instructors commented that "it's easier to rearrange tables and chairs...to pull tables over...and build hexagons," and "the class is designed to have students work in teams." In L1050's previous design, this approach would have been far more difficult and time consuming (and, as one instructor informed us, given the number of seats in the previous configuration, would typically have taken place outside of the classroom in smaller, dedicated "breakout" rooms), whereas in the modified design, with the reconfiguration of the desks and the reduction in seating from 60 to 40, the moving of desks and chairs was relatively easy. In contrast to Winter 2013, the instructors interviewed in Fall 2013 indicated that most of their course content was lecture-based. In terms of our conflicting findings, what this suggests is that the redesign of L1050 may have meant little to students taking lecture-based courses in the room, whereas students taking courses with more active learning approaches, which were more common in Winter 2013 than Fall 2013, were more likely to perceive the room as an improved learning space. 
Returning to the Sanders (2013) study referenced earlier, in which she argued that student engagement and classroom design cannot be studied without considering class format and learning objectives (p. 496), our interpretation that course content/delivery was consequential to reported perceptions of L1050 as an effective learning space is certainly consistent with Sanders' thesis. As we have noted, active learning approaches were more common in Winter 2013 than Fall 2013, and reported perceptions of the effectiveness of L1050 as a learning space were generally elevated during the former semester. Based on this we might argue that in response to our question concerning whether physical improvements to a classroom can be perceived to have a positive impact on the classroom as a learning space, our answer could be a qualified "maybe," with the caveat that only if the classroom is used in a manner for which the room was designed. Otherwise, physical improvements, assuming that minimal standards of comfort, sightlines, technology, etc. are already being met, may be relatively inconsequential to student engagement and learning. As one student commented in Fall 2013, "I like the set up but it's not like it really changes the overall learning experience that much". This may suggest that as universities and colleges increasingly move (or at least increasingly consider moving) to more active learning classrooms with the implicit expectation of "enhanced" or "better" learning experiences, those making these decisions should also be aware that physical changes to the classroom may have little, if any, consequence to student learning if traditional lecture-based pedagogies are maintained in rooms designed for more innovative teaching practices, in concert with the findings of Sanders (2013) noted earlier. Instead, we would argue that the alignment of design and pedagogy is a central consideration to any classroom modification and both need to be considered in tandem. In other words, changing the physical environment of the classroom appears to be worth doing if the change corresponds with subsequent changes to pedagogical practices.

An important consideration related to this is that the very notion of an "improved" classroom is in many respects subjective. As we noted earlier, Brooks (2011) and Hill and Epps (2010) used different criteria as to what constituted an "improved" classroom. This speaks to one of the central difficulties of classroom modifications; that is, for some students certain modifications will be seen as beneficial to their learning, while other modifications may be seen as detrimental (no doubt this holds true for instructors as well). One obvious example in the present study was the replacement of the projector and screen in L1050 with the two sidemounted LED displays. The fact that some students responded favourably to the two displays, while others found the use of a second display to be distracting speaks to the hazards of understanding "improvements" in isolation from teaching and learning practices. Overall, what this suggests is that without specific pedagogical goals in mind, or an explicit understanding of the kind of learning environment the instructor is trying to create, the very notion of "improvement" to the physical features of a room (again, beyond some minimal standards) may carry little meaning.

As a final point, we would be remiss if we did not speak to the fact that our measures of student engagement were not based on the assessment of achievement of actual learning outcomes but were instead based on students' reported perceptions of the room as an effective learning space. This is a notable limitation, since it is possible that classrooms that are perceived as effective learning environments have little or no bearing on how well students actually perform in the classroom, as suggested by Hill and Epps (2010). To address this question would require information on learning outcomes, including student grades, in the same course that was taught in the same classroom before and after physical modifications were made to the room, Journal of the Scholarship of Teaching and Learning, Vol. 16, No. 1, February 2016. 
Perks, Orr, and Alomari

with grades likely needing to be averaged out over many years to account for year-to-year fluctuations. As researchers will no doubt appreciate, such a design would be challenging, and the paramount question of whether it is worthwhile examining the consequences of room changes in isolation of pedagogical considerations remains. As such, unpacking this possibility that perceptions of learning and achievement of actual learning outcomes do not necessarily correlate - remains an open research question. The results presented here, then, should not be seen as a definitive examination of the importance of classroom design, but should instead be seen as a study that compliments the existing, and growing research literature examining the relevance of classroom design to student learning.

\section{Acknowledgements}

We gratefully acknowledge the University of Lethbridge for its support and funding for this project, as well as the contributions of numerous members of the research team, including, in particular, Bernie Wirzba, Jeff Meadows, and Victoria Holec.

\section{References}

Armbruster, P., Patel, M., Johnson, E., \& Weiss, M. (2009). Active learning and student-centered pedagogy improve student attitudes and performance in introductory biology. CBE - Life Sciences Education, 8(3), 203-213.

Barr, R. B., \& Tagg, J. (1995). From teaching to learning: A new paradigm for undergraduate education. Change, 27(6), 13-25.

Beichner, R., Saul, J. M., Abbott, D. S., Morse, J. J., Deardorff, D. L., Allain, R. J., Bonham, S. W., Dancy, M. H., \& Risley, J. S. (2007). The Student-centered activities for large enrollment undergraduate programs (SCALE-UP) project. In E. F. Redish \& P. J. Cooney (Eds.), ResearchBased Reform of University Physics (pp. 1-42). College Park, MD: American Association of Physics Teachers.

Bergtrom, G. (2011). Content vs. learning: An old dichotomy in science courses. Journal of Asynchronous Learning Networks, 15(1), 33-44.

Boddington, A., \& Boys, J. (Eds.). (2011) Re-shaping learning: A critical reader: The future of learning spaces in post-compulsory education. Rotterdam: Sense.

Boys, J. (2011). Towards creative learning spaces: Rethinking the architecture of postcompulsory education. New York: Routledge.

Brooks, D. C. (2011). Space matters: The impact of formal learning environments on student learning. British Journal of Educational Technology, 42(5), 719-726. doi: 10.1111/j.14678535.2010.01098.x

Brown, J. S. (2006). New learning environments for the $21^{\text {st }}$ century: Exploring the edge. Change: The Magazine of Higher Learning, 38(5), 18-24.

Journal of the Scholarship of Teaching and Learning, Vol. 16, No. 1, February 2016.

Josotl.Indiana.edu 
$\underline{\text { Perks, Orr, and Alomari }}$

Clark, H. (2002). Building education: The roll of the physical environment in enhancing teaching and research. London: Institute of Education.

Cornell, P. (2002). The impact of changes in teaching and learning on furniture and the learning environment. New Directions for Teaching and Learning, 92, 33-42. doi: 10.1002/t1.77

Dori, Y. J., Belcher, J., Bessette, M., Danziger, M., McKinney, A. \& Hult, E. (2003). Technology for active learning. Materials Today, 6(12), 44-49.

Freire, P. (2004). Pedagogy of the oppressed (M. B. Ramos, Trans.). New York: Continuum. (Original work published 1970).

Giroux, H. (1981). Ideology, culture, and the process of schooling. Philadelphia, PA: Temple University Press.

Harrison, A., \& Hutton, L. (2014). Design for the changing education landscape : Space, place and the future of learning. New York: Routledge.

Hill, M. C., \& Epps, K. K. (2010). The impact of physical classroom environment on student satisfaction and student evaluation of teaching in the university environment. Academy of Educational Leadership Journal, 14(4), 65-79.

Hooks, B. (1994). Teaching to transgress: Education as the practice of freedom. New York: Routledge.

Jamieson, P. (2003). Designing more effective on-campus teaching and learning spaces: A role for academic developers. International Journal for Academic Development, 8(1/2), 119-133.

Kember, D. (2009). Promoting student-centred forms of learning across an entire university. Higher Education: The International Journal of Higher Education and Educational Planning, $58(1), 1-13$.

Lizzio, A., Wilson, K., \& Simons, R. (2002). University students' perceptions of the learning environment and academic outcomes: Implications for theory and practice. Studies in Higher Education, 27(1), 27-52.

Macedo, D. (1994). Literacies of power: What Americans are not allowed to know. Boulder, CO: Westview.

McLaren, P. (1989). Life in schools: An introduction to critical pedagogy in the foundations of education. New York: Longman.

Muthyala, R. S., \& Wei, W. (2013). Does space matter? Impact of classroom space on student learning in an organic-first curriculum. Journal of Chemical Education, 90(1), 45-50.

Journal of the Scholarship of Teaching and Learning, Vol. 16, No. 1, February 2016.

Josotl.Indiana.edu 
Neuman, W. L. (1997). Social research methods (3 ${ }^{\text {rd }}$ ed.). Needham Heights, MA: Allyn \& Bacon.

Oblinger, D. G. (Ed.). (2006) Learning spaces. Educause. Retrieved from https://net.educause.edu/ir/library/pdf/PUB7102.pdf

Perks, T. (2014). What makes a classroom an effective learning environment? Light on Teaching, (2013-14 Issue), 1-4. Retrieved from http://www.uleth.ca/teachingcentre/what-makesclassroom-effective-learning-environment

Ross, K. C. (2013). Creating dialogical spaces in blend environments: A case study of classroom design in two English literature courses. In L. Kyei-Blankson \& E. Ntuli (Eds.), Practical applications and experiences in K-20 blended learning environments (pp. 280-294). Hershey, PA: IGI Global.

Sanders, M. J. (2013). Classroom design and student engagement. Proceedings of the Human Factors and Ergonomics Society 57 ${ }^{\text {th }}$ Annual Meeting, 496-500. doi: $10.1177 / 1541931213571107$

Temple, P. (2008). Learning spaces in higher education: An under-researched topic. London Review of Education, 6(3), 229-241.

Van Note Chism, N. (2006). Challenging traditional assumptions and rethinking learning spaces. In D. G. Oblinger (Ed.), Learning spaces. Educause. Retrieved from https://net.educause.edu/ir/library/pdf/PUB7102.pdf

Journal of the Scholarship of Teaching and Learning, Vol. 16, No. 1, February 2016. 